\title{
A Second Look at Subjective Wellbeing Using Differential Item Functioning
}

\author{
Karen H. Larwin' ${ }^{1}$ and Milton Harvey ${ }^{2}$
}

\begin{abstract}
The current investigation uses latent variable modeling to investigate Subjective Well-Being (SWB).

As a follow-up to Larwin, Harvey, and Constantinou (2020), subjective wellbeing is presented through third-order factor model, which explains two-second order factors, SWB and Interpersonal Experiences (IES) while incorporating measures of relationship and resiliency self-evaluations. Additionally, the current investigation considers differential item functioning not considered in the existing SWB literature.

JEL classification numbers: $\mathrm{C} 1, \mathrm{C} 3, \mathrm{C} 4, \mathrm{C} 9$.

Keywords: Subjective Well-Being, Satisfaction with Life Scale, Subjective Happiness Scale, Brief Resiliency Scale, Relationship Assessment Scale, Multiple Indicators Multiple Causes (MIMIC), Weighted least squares mean variance adjusted estimator (WLSMV).
\end{abstract}

1 Youngstown State University, USA.

${ }^{2}$ Kent State University, USA.

Article Info: Received: May 1, 2021. Revised: May 19, 2021.

Published online: May 25, 2021. 


\section{Introduction}

Happiness and unhappiness have been topic a large body of research. Diener (1984) theorized that how an individual evaluated their state of happiness was based on their overall evaluation of their well-being by considering their general satisfaction with life, in considering both the positive and negative aspects of their experiences. This subjective well-being (SWB) has been investigated using various models, however, Busseri \& Sadava (2011) theorized a model of subjective well-being that most closely aligned with Diener conceptualization.

While Diener's proposition about SWB incorporated both the positive and negative aspects, or what he described as the cognitive aspects of SWB, he did not consider interpersonal experiences that can have an impact of the individual's evaluation. Larwin, Harvey, and Constantinou (2020) posit that to fully embrace the whole SWB of the individual, both personal relationship and interpersonal experiences, or personal challenges, must come into the consideration. This proposition is supported by a number of investigations concluding that personal relationships and recovery from setbacks in life influence SWB (e.g., Achour \& Nor, 2014; Badran \& Youssef-Morgan, 2015; Mahmood \& Ghaffar, 2014; Patil \& Adsul, 2017; Robbins, Ford, \& Tetrick, 2011; Sagone \& Caroli, 2014; Souri \& Hasanirad, 2011). As such, the current investigation focuses on the cognitive aspects of SWB - life satisfaction (LS) that entails how a person thinks globally about his or her happiness and life as well as those interpersonal factors that impact an individual's SWB. To measure the cognitive aspects of SWB, two inventories, the Satisfaction with Life Scale (SWL) and Subjective Happiness Scale (SHS) are used. To capture the influence of interpersonal experiences (IES) on SWB, two inventories, the Brief Resiliency Scale and the Relationship Assessment Scale are used.

As a continuation of the Larwin et al (2020), this investigation examines the stability of the previously presented analyses in a third order MIMIC Model. Assessment of DIF and MIMIC DIF is valuable as observed by Brown (2006) that the "significant direct effect of the dummy code on an indicator is evidence of measurement noninvariance" (p. 268) and group differences on the indicator's intercept is evidence of differential item functioning. MIMIC DIF is the consideration of effects of covariates on individual items (manifest variables) after controlling for the overall impact of the covariates on that construct.

First, this presentation uses CFI to assess whether the same models presented in Larwin et al. (2020) converge significantly when covariates are included in the model. This will be based upon the single-factor MIMIC (Multiple Indicators Multiple Causes) model (Jöreskog \& Goldberger, 1975). It is a model "in which multiple indicators reflect the underlying latent variables/factors, and the multiple causes (observed predictors) affect latent variables/factors" (Wang \& Wang, 2012, p. 90). For this goal, a single MIMIC model is utilized. Applications of MIMIC models are widespread, ranging from economics (Chaudhuri, Kumbhakar, \& Sundaram, 2016) to psychology (Proitsi et al., 2011) and even public health (RíosBedoya, Pomerleau, Neuman, \& Pomerleau, 2009). Many of these applications used 
a one-dimension MIMIC model, but some others have used two-dimension MIMIC Models (Guan, 2017). Besides addressing the fit of each of the four scales and three composite models, the statistical significance of the loadings of the predictors is provided. Secondly, the current investigation will examine the effects of analyzing heterogeneous empirical data by factor analytic models that assume data homogeneity, in effect the MIMIC model. Lastly, the analyses will examine the effects of analyzing heterogeneous empirical data by factor analytic models that assume data homogeneity; The MIMIC-DIF effects.

\section{Methods}

\subsection{Participants}

The data for the current investigation is a convenience sample of 851 respondents, primarily current and former students at a university in northeastern Ohio. Participants were invited to complete the survey through an email invitation sent out by a professor who works at a NE Ohio university. This invitation was sent to students, recent graduates, and fellow faculty members. Participants were asked to share the survey link with their co-workers and friends.

The respondents were mostly white $(91.2 \%)$, female $(89.1 \%)$, under the age of 50 years of age $(72.6 \%)$, and a predominately married $(73.4 \%)$.

Most of the respondents indicated that they were educated, with $58.6 \%$ showing that they have some post-undergraduate education, and $21.2 \%$ indicating that they have an undergraduate-level degree. Geographically, $47.4 \%$ resided in cities and villages while $52.6 \%$ lived in the suburbs.

\subsubsection{Instruments}

The current investigation incorporates four happiness scales (SWL, SHS, BRS, RAS). Basic demographic information was also collected, age, gender, relationship status, education, occupation, the geography of residence, and current socioeconomic status.

SWL consists of five items rated on a 7-point Likert scale ranging from strongly disagree (1) to strongly agree (7).

The items include:

(1) In most ways, my life is close to my ideal;

(2) The conditions of my life are excellent;

(3) I am satisfied with my life;

(4) So far, I have gotten all the important things in life; and

(5) If I could live my life over, I would change almost nothing.

This scale is intended to be a unidimensional measure of satisfaction with life. However, to achieve unidimensionality, some empirical studies correlate some error covariances among some items (e.g., Pavot \& Diener, 1993; Slocum-Gori, Zumbo, Michalos, \& Diener, 2009). The validity and reliability of SWL have been established in different socio-economic conditions and cultures (Busing \& West, 2016; Diener et al., 1985; Diener, Inglehart, \& Tay, 2013; Tay, Ng, Kuykendall, \& 
Diener, 2014; Vela, Lerma, \& Ikonomopoulos, 2017) and different demographic groups (López-Ortega, Torres-Castro, \& Rosas-Carrasco, 2016; Lucas-Carrasco, Den Oudsten, Eser, \& Power, 2014). The SWL is a very stable measure and has been found to perform better than single variable measures of satisfaction with life (Andrews \& Withey, 1976; Eid \& Diener, 2006; Krueger \& Schkade, 2008).

SHS consists of four items rated on a 7-point Likert scale.

The items include:

(1) In general, I consider myself... Not a very happy person (1) to A very happy person (7);

(2) Compared with most of my peers, I consider myself... Less happy (1) to More happy (7);

(3) Some people are generally very happy. They enjoy life regardless of what is going on, getting the most out of everything. To what extent does this characterization describe you? Not at all (1) to A great deal (7); and

(4) Some people are generally not very happy. Although they are not depressed, they never seem to be happy as they might be. To what extent does this characterization describe you? Responses: Not at all (1) to A great deal (7).

Despite its brevity, SHS has good psychometric qualities; it is characterized by "high internal consistency, a unitary structure, and stability over time" (Lyubomirsky, 2008). Based on Lyubomirsky (2008), the reliability estimates for the scale ranged from $\alpha=.79$ to $\alpha=.94$.

The BRS consisting of six items on a 5-point Likert-type scale ranging from strongly disagree (1) to strongly agree (5) (Tansey et al., 2016).

Items include:

(1) I tend to bounce back quickly after hard times;

(2) I have a hard time making it through stressful events;

(3) It does not take me long to recover from a stressful event;

(4) It is hard for me to snap back when something bad happens;

(5) I usually come through difficult times with little trouble; and

(6) I tend to take a long time to get over set-backs in my life

The RAS consisting of seven items on a 5-point Likert-type has exhibited high internal reliability (Tansey et al., 2016).

The items include:

(1) In general, how satisfied are you with your relationship?;

(2) How good is your relationship compared to most?;

(3) How often do you wish you hadn't gotten into this relationship?;

(4) To what extent has your relationship met your original expectations?;

(5) How much do you love your partner?; and

(6) How many problems are there in your relationship?

This instrument exhibits good internal consistency $(\alpha=.73$ to .92$)$ across different demographic groups and when administered in different languages (Dinkel \& Balck, 2005). Even when applied to multiple types of relationships the RAS provides a stable measure "when completed with regards to romantic partners, parents, friends, and other types of relatives" (Renshaw et al., 2011). 


\section{Data Analysis Procedures}

First, this presentation uses CFI to assess whether the same models presented in Larwin et al. (2020) converge significantly when covariates are included in the model. Secondly, the current investigation examines the effects of analyzing heterogeneous empirical data by factor analytic models that assume data homogeneity, in effect the MIMIC model. Lastly, the analyses will examine the effects of analyzing heterogeneous empirical data by factor analytic models that assume data homogeneity; The MIMIC-DIF effects. This is accomplished through coding dummy variables. Justifying dummy coding, Mast and Lichtenberg (2000, p. 56) wrote thus: "Dichotomizing these items not only provides for a simpler interpretation of the influence of these items, but it is also consistent with the conceptualization of these items as reflecting group membership." The model was tested above using this MIMIC rendition of the model.

\subsection{The Issues of Homogeneity - MIMIC}

The seven-factor analytical models assume that the population is homogeneous. As observed earlier, one of the characteristics of data used by behavioral scientists is variability. The sample is not homogeneous; an assumption of the factor analysis models proposed above. As pointed out by Muthen (1989, p. 558), researchers often analyze such data "as if they were obtained from a single population, although it is often unlikely that all individuals in our sample have the same set of parameter values." However, standard measurement models such as factor analysis that assume population homogeneity "may not be realistic across subsets of the group studied," and "ignoring to account for unobserved heterogeneity can lead to biased parameter estimates and therefore can yield distorted results." (Ansari, Jedidi, \& Dube, 2002, p. 49). A form of structural equation modeling, multiple indicatorsmultiple causes (MIMIC) confirmatory factor analysis, is used to assess population heterogeneity in the four scales used in this paper. Many scholars examined this issue in existing scales (Christensen et al., 1999; Gallo, Rabins, \& Anthony, 1999; Mast \& Lichtenberg, 2000). As Brown (2006, p. 268) wrote, "a significant direct effect of the dummy code (covariates) on the latent factor indicates population heterogeneity (group differences on latent means)." When the MIMIC model is used to evaluate heterogeneity is called, just, MIMIC (Lee, Little, \& Preacher, 2011).

For assessing population heterogeneity, first, transform the covariates into binary variables, then fit single construct MIMIC models then test the overall fit of the model using the criteria above (RMSEA, CFI, and TLI). Then identify statistically significant associations between the exogenous causal variable and the latent variable; an indicator that the factor means are different for different levels of regressor (Wang \& Wang, 2012). 


\subsection{Assessment of DIF and MIMIC DIF}

As Brown observed (2006, p. 268) "a significant direct effect of the dummy code on an indicator is evidence of measurement non-invariance (group differences on the indicator's intercept, i.e., differential item functioning.)" The former is simply called MIMIC, and the latter is MIMIC DIF (Lee et al., 2011). Other discussions of MIMIC and MIMIC DIF are by Christensen et al. and Gallo, Rabins, and Anthony (Christensen et al., 1999; Gallo et al., 1999). Unlike DIF, that is the significant direct effect of a covariate on a latent variable (construct), MIMIC DIF is the considerable effects of covariates on individual items (manifest variables) after controlling for the overall impact of the covariates on that construct. Raykov, Marcoulides, Lee, and Chang (2013) reported a Mplus code for calculating MIMIC DIF. Similar to Christensen et al. (1999), the associated 95\% bootstrap confidence intervals for 5,000 generated replications.

\section{Results}

Based on Larwin et al.(2020) all three models were demonstrated to be equally tenable, because the fit indices indicate that each model fits the data and the factor loadings for all four scales are significantly different zero at the.01 confidence level. Taken together, it was demonstrated that the correlated four-factor model fits the data best.

Therefore, the focus of this presentation is the development and testing of three models: MIMIC as a Regression model with categorical predictors, MIMIC as a Regression model with binary predictors for heterogeneous covariates, and MIMIC as a Regression model with binary predictors for differential item functioning (DIF) covariates.

\subsection{MIMIC as a Regression model with categorical predictors - MIMIC DIF}

Basic MIMIC model with categorical predictors for each individual construct is presented. As discussed earlier, scholars use categorical MIMIC Models widely to explain and predict constructs. Here six covariates were used to explain each of the seven psychological (single, aggregate, or composite) constructs. For each scale, the fit of the unidimensional model is discussed, followed by the results of the regression of the covariates on the constructs. Table 1 summarizes the results for unidimensional MIMIC models. 
Table 1: MIMIC Models for Categorical Covariates

\begin{tabular}{|c|c|c|c|c|c|c|c|c|}
\hline Values & SWL & SHS & RAS & BRS & \multicolumn{2}{|c|}{$\begin{array}{c}\text { SWB } \\
\text { [SWL,SHS] }\end{array}$} & \multicolumn{2}{|c|}{$\begin{array}{c}\text { IES } \\
{[\text { RAS,BRS] }}\end{array}$} \\
\hline$\chi^{2},(d f)$ & $\begin{array}{c}49.33 \\
(28)\end{array}$ & $\begin{array}{c}34.71 \\
(19)\end{array}$ & $\begin{array}{c}163 . .61 \\
(48)\end{array}$ & $\begin{array}{c}52.78 \\
(38)\end{array}$ & \multicolumn{2}{|c|}{$\begin{array}{c}225.97 \\
(67)\end{array}$} & \multicolumn{2}{|c|}{$\begin{array}{c}608 \\
(128)\end{array}$} \\
\hline $\begin{array}{l}\text { RMSEA } \\
90 \% \text { CI }\end{array}$ & $\begin{array}{c}.03 \\
.02, .04\end{array}$ & $\begin{array}{c}.03 \\
.01, .05\end{array}$ & $\begin{array}{c}.05 \\
.04, .06\end{array}$ & $\begin{array}{c}.02 \\
.00, .03\end{array}$ & \multicolumn{2}{|c|}{$\begin{array}{c}.05 \\
.05, .06\end{array}$} & \multicolumn{2}{|c|}{$\begin{array}{c}.07 \\
.06, .07\end{array}$} \\
\hline CFI & .998 & .999 & .996 & .999 & \multicolumn{2}{|c|}{.993} & \multicolumn{2}{|c|}{.986} \\
\hline TLI & .998 & .998 & .995 & .998 & \multicolumn{2}{|c|}{.991} & \multicolumn{2}{|c|}{.982} \\
\hline & & & & & SWL & SHS & BRS & $\mathbf{R A S}^{+}$ \\
\hline \multirow[t]{2}{*}{ Age } & -.09 & .05 & -.14 & .08 & -.09 & .05 & .08 & -.13 \\
\hline & $(.03)^{*}$ & $(.03)$ & $(.03)^{*}$ & $(.03)^{*}$ & $(.03)^{*}$ & $(.03)$ & $(.02)^{*}$ & $(.03)^{*}$ \\
\hline \multirow[t]{2}{*}{ Gender } & .12 & .04 & .10 & .29 & .13 & .04 & .32 & .09 \\
\hline & $(.11)$ & $(.10)$ & $(.12)$ & $(.09)^{*}$ & $(.11)$ & $(.10)$ & $(.10)^{*}$ & $(.11)$ \\
\hline \multirow[t]{2}{*}{ Marital } & .40 & .16 & .70 & .10 & .41 & .16 & .12 & .67 \\
\hline & $(.07)^{*}$ & $(.08)$ & $(.08)^{*}$ & $(.07)$ & $(.08)^{*}$ & $(.08)$ & $(.07)$ & $(.08)^{*}$ \\
\hline \multirow[t]{2}{*}{ Educ. } & .11 & .06 & .02 & .08 & .11 & .06 & .09 & .02 \\
\hline & $(.04)^{*}$ & $(.04)$ & $(.045)$ & $(.04)$ & $(.04)^{*}$ & $(.04)$ & $(.04)$ & $(.04)$ \\
\hline \multirow[t]{2}{*}{ Job (Occ) } & .07 & .07 & .07 & -.03 & .07 & .07 & -.03 & .07 \\
\hline & $(.04)$ & $(.04)$ & $(.04)$ & $(.03)$ & $(.04)$ & $(.04)$ & $(.04)$ & $(.04)$ \\
\hline \multirow[t]{2}{*}{ SES } & -.19 & -.17 & -.08 & -.11 & -.20 & -.17 & -.12 & -.07 \\
\hline & $(.03)^{*}$ & $(.03)^{*}$ & $(.03)$ & $(.03)^{*}$ & (.03) & $(.00)^{*}$ & $(.03)^{*}$ & $(.03)$ \\
\hline $\mathrm{R}^{2}$ & & & & & .75 & 63 & .08 & 13 \\
\hline
\end{tabular}

\subsection{Single MIMIC Models}

Satisfaction with Life Scale (SWL). The results of fitting a single dimension to the data for the five items of this scale show that they fit all the requirements of a good model using a weighted least square mean and variance adjusted estimator (WLSMV).

Results indicate WLSMV $\chi 2(49.33, \mathrm{df}=28, \mathrm{~F}$-value $=0.0077, \mathrm{RMSEA}=.030$, $\mathrm{CI}_{90 \%}[.015-.043], \mathrm{CFI}=.998, \mathrm{TLI}=0.998$. SWL explained significant portions of each of the five observed variables. The residual variance is highest for swl5 $(0.548)$ 'If I could live my life over, I would change almost nothing' and lowest (0.124) for swl3 'I am satisfied with my life.' The regression component of this MIMIC model indicates that the six predictors explain a significant portion ( $\mathrm{p}>.001$ ), about $13.1 \%$ of the variance in SWL. Four of the six predictors (age, marital status, education level, and socioeconomic status) are all significant at $\mathrm{p}<.01$. Furthermore, the average SWL score is inversely related to age and SES but positively affected by marital status (higher for married respondents) and with individuals in non-medical related jobs. 
Subjective Happiness Scale (SHS). For this one-factor model fits the data adequately fits the data; with WLSMV $\chi 2(34.705$, df $=19)$, F-value $=.0152$, RMSEA $=.031$, CI90\%[.014-.047], CFI $=.999$ and TLI $=.998$. Using shs1 as scale (loading of one), the other three are significantly explained by this SHS construct. The residual variance is highest for shs4 (.531): 'Some people are generally not very happy. Although they are not depressed, they never seem to be happy as they might be. To what extent does this characterization describe you?' and lowest for shs 3 (.170) 'Some people are generally not very happy. Although they are not depressed, they never seem to be happy as they might be. To what extent does this characterization describe you?' The regression part of this model shows that the six predictors account only $7.3 \%$ of SHS, but this variance is significantly different from zero, and the effects of two predictors (age and SES) are significant at the.01 level; positive for age and negative for SES. Both marital status and job types are significant at the.05 level. The average SHS scores are higher for married respondents and those employed in non-healthcare related jobs.

Brief Resilience Scale (BRS). We fitted a unidimensional factor to the six items that constitute this scale, and the results show an adequate fit: WLSMV $\chi 2(52.778$, $\mathrm{df}=38, \mathrm{~F}$-value $=.056, \mathrm{RMSEA}=.021$, CI90\%[.000-.034), CFI $=.999, \mathrm{TLI}=.998$. We used the item brs1 for scale, and the results indicated that BRS loads significantly on the remaining five items. However, the largest residual variance was brs5 'I usually come through difficult times with little trouble,' and the lowest residual variance is for brs6 'I tend to take a long time to get over setbacks in my life.' The six covariates account for $8.7 \%$ of the variance in construct BRS, but only three of these predictors are statistically different from zero at 0.01 level - age, gender, and socio-economic status of the respondent. Average BRS scores are higher for older than younger respondents, extremely higher for females than males, but lower for high-income respondents.

Relationship Assessment Scale (RAS). We fitted a unidimensional factor to the seven items that constitute this scale. The results showed an adequate fit: WLSMV $\chi 2(163.61, \mathrm{df}=48, \mathrm{~F}$-value $=0.001), \mathrm{RMSEA}=.053 \mathrm{CI} 90 \%[.044-.062], \mathrm{CFI}=.996$, $\mathrm{TLI}=.995$. Using ras 1 as a scale with an unstandardized loading of one, this RAS construct converged on the seven items. The lowest residual variance was for ras 2 (0.06) 'In general, how satisfied are you with your relationship?' and the largest with ras7 $(0.72)$ 'How many problems are there in your relationship?' The six covariates significantly $(\mathrm{p}>.01)$ explained $12.8 \%$ of the variance in RAS. Two of the predictors, age, and marital status have opposite effects on the average RAS scores; age is negatively associated with higher average RAS scores for younger respondents, and higher for married individuals.

Multi-construct MIMIC Models. Like covariate structural equations above, there are two multifactor models tested: Subjective Well-Being Scale and the Interpersonal Experiences Scale (IES). The Subjective Well-Being Scale (SWB) is 
a second-order scale and is a composite SWL and SHS, consisting of nine items. This composite unidimensional model fits the data with an RMSEA value of .050 with a tight confidence band, $\mathrm{CI}_{90 \%[}[.042, .057]$. Also, the CFI and TLI values are higher than .99 . The six covariates explain $13.9 \%$ of the variability in SWB. Since this model is a combination of two single MIMIC models, their contributions to this composite model are separate (see Table 1, columns 6 and 7). For the coefficients for SWL three are significant at the at .01 level: age of respondents, marital status (higher for married) and higher for the more educated. For the SHS construct only SES (higher for low-status individuals). Since this construct is a composite, it also explains portions of the variances in SWL (74.9\%) and SHS (62.7\%).

The Interpersonal Experiences Scale (IES) is a second-order scale and is a composite of RAS and BRS, consisting of thirteen items. This model fitted the data with an RMSEA of .066, and a relatively tight, CI $90 \%[.061, .072]$ and CFI and TLI are greater than .98 . The effects of the covariates vary between BRS and RAS. For the former, the significant covariates are the negative effect of age. However, the effect of marital status on this second-order constructs via SWB is higher for married respondents and individuals with higher SES. The effect of RAS on IES through age is negative but positive for marital status; it is higher for marital respondents. The effects these lower-order constructs on IES second-order vary; $12.8 \%$ for RAS but only $7.7 \%$ for BRS.

\subsection{Third Order Hierarchical MIMIC Models (The Super Composite Construct - SWB and IES)}

We proposed and tested three such models. Figures 1 to 3 present a summary of the results. Figure 1 illustrates the single third-order hierarchical model. 


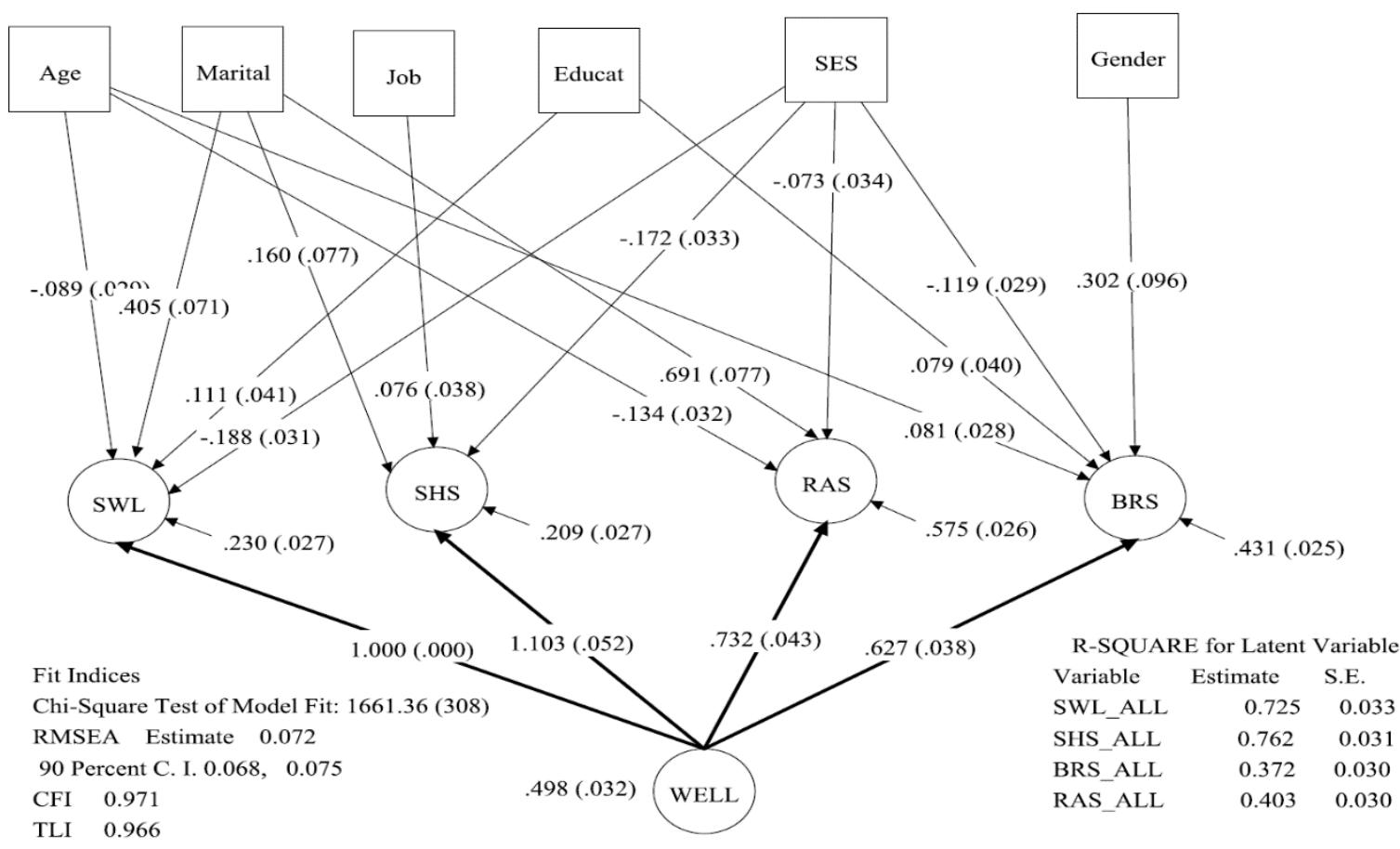

\section{Figure 1: Hierarchical Low Order MIMIC Structure of Single Second MIMIC Order Factor}

Figure 2, presents the hierarchical MIMIC model of four-factor correlated constructs.

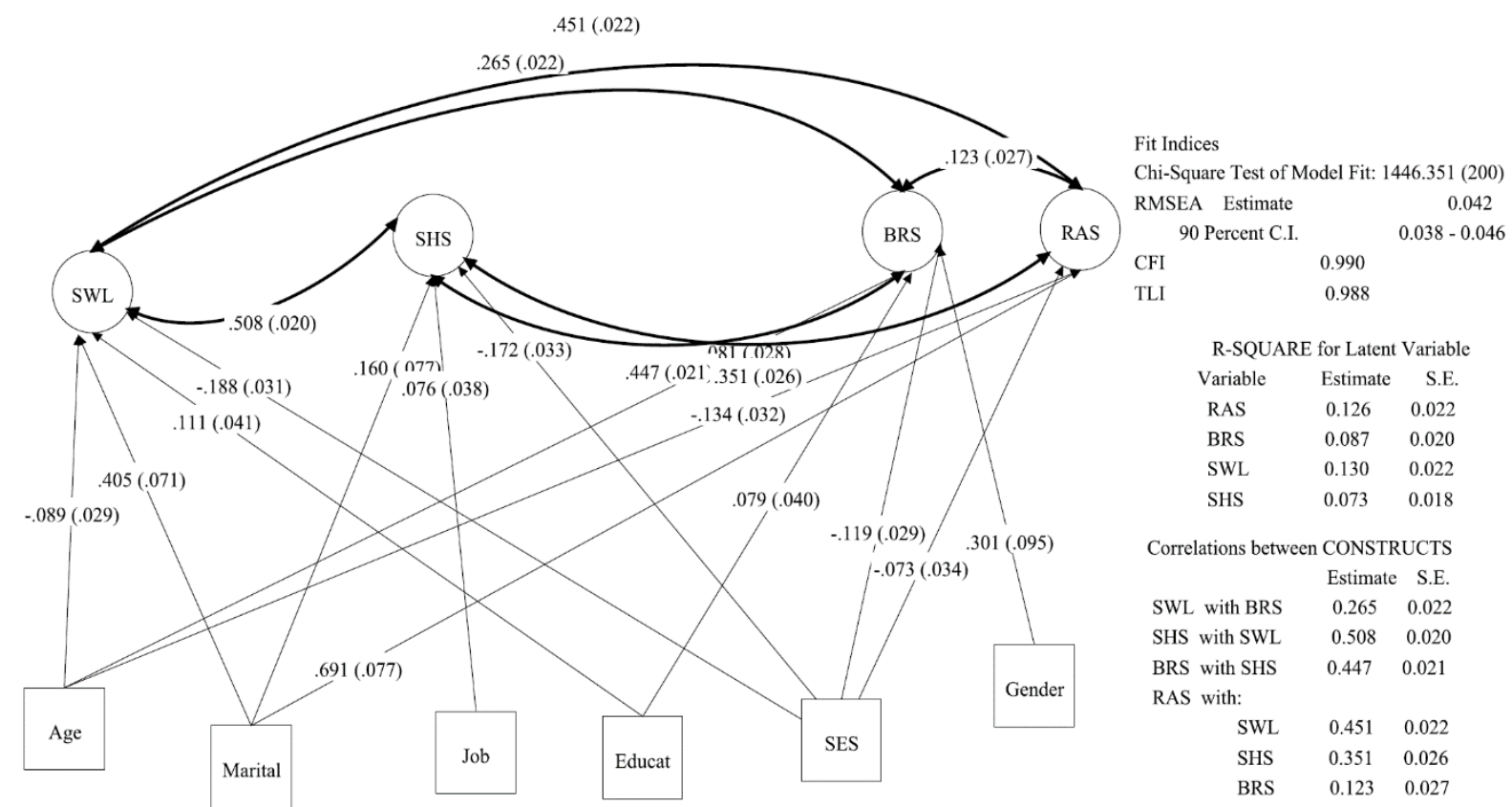

Figure 2: Hierarchical MIMIC Structure of Four Correlated Constructs 
Figure 3, shows the hierarchical structure of two correlated second-order constructs.

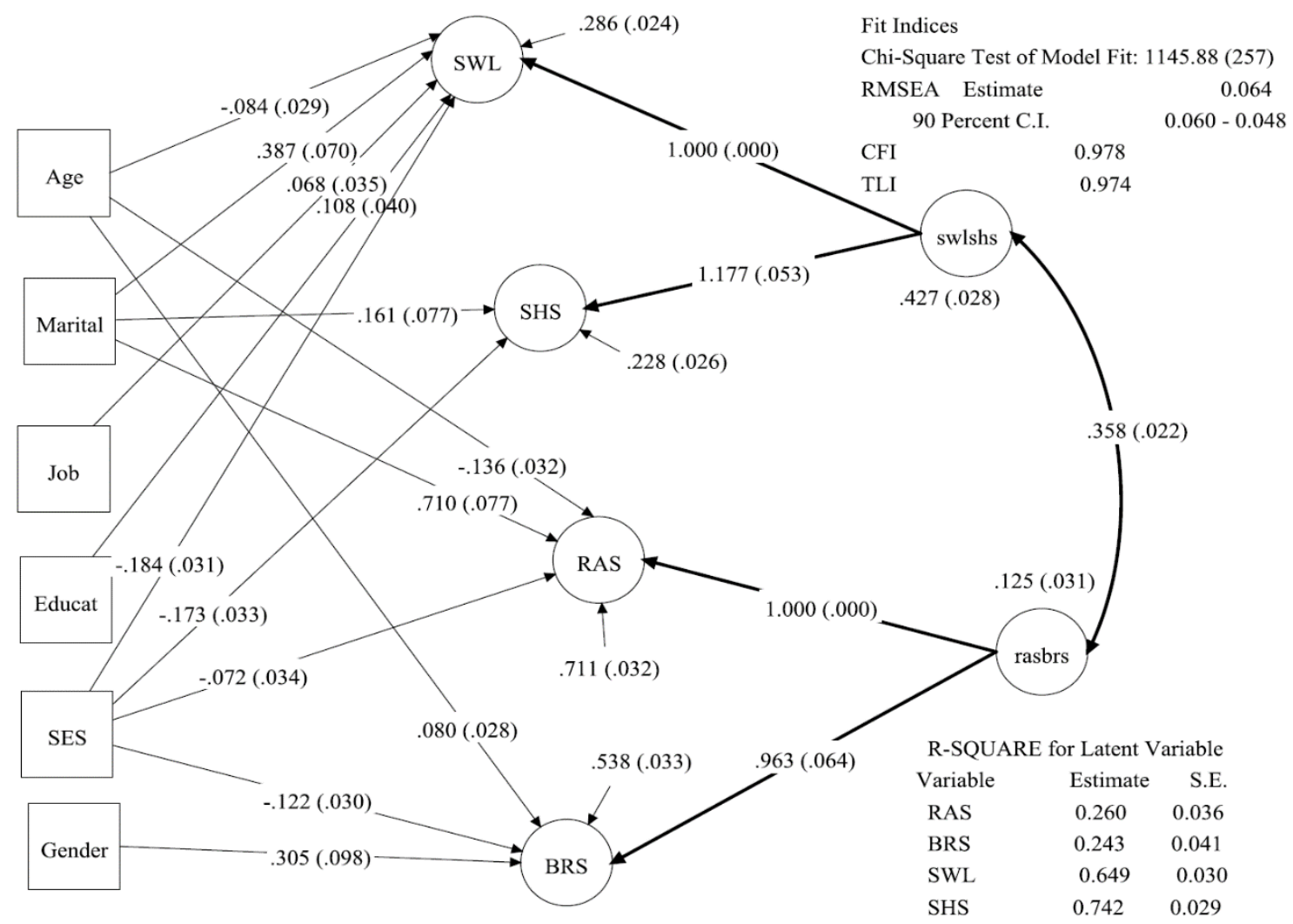

Figure 3: Hierarchical Structure of Two Correlated Second Order Constructs

Based on the measures of model-fit, all three models fit the data, but the hierarchical four-factor correlated model has the best-fit indices (Figure 2). However, the single third-order model contributed most to the effects of the lower-order constructs (Figure 1).

\subsection{Assessment of Predictor-Heterogeneity (Covariates and Construct)}

As discussed earlier, six independent variables (covariates) were converted into binaries ( 0 and1), and then we recomputed the same MIMIC seven models. Significant effects of covariates on the construct indicate heterogeneity of those predictors. For example, Mast \& Lichtenberg (2000) used this method in assessing the effects of age, depression, and gender on motor and cognition latent variables. The same approach was used in investigating the effects of six covariates (age, gender, marital status, education, type of job, and socioeconomic status) on each of the four independent constructs (SWL, SHS, RAS and BRS, and the three composite 
constructs (SWB [SWL, SHS], IES [RAS, BRS] and the third-order construct SUPER [SWB, IES]. The unstandardized coefficients were reported because the numbers can be interpreted in their original metric (Christensen et al., 1999; Mast $\&$ Lichtenberg, 2000). Table 2 summarizes these results where heterogeneous covariates (direct effects) are bold row titles together with their 95\% bootstrap confidence intervals.

Table 2: DIF Analysis by Covariates on CONSTRUCTS and Items in SWL, SHS, BRS and RAS Scales

\begin{tabular}{|c|c|c|c|c|c|c|}
\hline $\begin{array}{l}\text { Endogenous } \\
\text { Indicators } \\
\text { Items }\end{array}$ & Age & Gender & Marital & Educ & Job & SES \\
\hline SWL & $\begin{array}{c}-.16 \\
(-.29,-.03)\end{array}$ & $\begin{array}{c}-.18 \\
(-.39, .02)\end{array}$ & $\begin{array}{c}.43 \\
(.28, .58)\end{array}$ & $\begin{array}{c}.20 \\
(.06, .33)\end{array}$ & $\begin{array}{c}-.01 \\
(-.14, .13)\end{array}$ & $\begin{array}{c}.35 \\
(.20, .48)\end{array}$ \\
\hline SWL(1) & $\begin{array}{c}.14 \\
(.05, .23)\end{array}$ & $\begin{array}{c}.14 \\
(.00, .28)\end{array}$ & $\begin{array}{c}-.03 \\
(-.13, .08)\end{array}$ & $\begin{array}{c}.08 \\
(-.01, .07)\end{array}$ & $\begin{array}{c}.02 \\
(-.07, .11)\end{array}$ & $\begin{array}{c}-.08 \\
(-.17, .02)\end{array}$ \\
\hline SWL(2) & $\begin{array}{c}.76 \\
(.79, .23)\end{array}$ & $\begin{array}{c}-.05 \\
(-.04, .05)\end{array}$ & $\begin{array}{c}-.10 \\
(-.22, .01)\end{array}$ & $\begin{array}{c}.06 \\
(.20, .11)\end{array}$ & $\begin{array}{c}.00 \\
(-.09, .10)\end{array}$ & $\begin{array}{c}.06 \\
(-.03, .17)\end{array}$ \\
\hline SWL(3) & $\begin{array}{c}-.03 \\
(-.11, .05)\end{array}$ & $\begin{array}{c}-.02 \\
(-.16, .11)\end{array}$ & $\begin{array}{c}-.09 \\
(-.20, .01)\end{array}$ & $\begin{array}{c}-.07 \\
(-.16, .10)\end{array}$ & $\begin{array}{c}.03 \\
(-.06, .12)\end{array}$ & $\begin{array}{c}.01 \\
(-.08, .10)\end{array}$ \\
\hline SWL(4) & $\begin{array}{c}-.10 \\
(-.21, .01)\end{array}$ & $\begin{array}{c}.14 \\
(-.03, .30)\end{array}$ & $\begin{array}{c}.22 \\
(.08, .34)\end{array}$ & $\begin{array}{c}-.08 \\
(-.18, .04)\end{array}$ & $\begin{array}{c}-.02 \\
(-.13, .10)\end{array}$ & $\begin{array}{c}-.12 \\
(-.08, .16)\end{array}$ \\
\hline SWL(5) & $\begin{array}{c}-.04 \\
(-.15, .07)\end{array}$ & $\begin{array}{c}-.04 \\
(-.03, .06)\end{array}$ & $\begin{array}{c}.04 \\
(-.09, .18)\end{array}$ & $\begin{array}{c}-.09 \\
(-.21, .03)\end{array}$ & $\begin{array}{c}-.05 \\
(-.16, .08)\end{array}$ & $\begin{array}{c}-.05 \\
(-.17, .08)\end{array}$ \\
\hline SHS & $\begin{array}{c}.07 \\
(-.07, .21)\end{array}$ & $\begin{array}{c}-.10 \\
(-.32, .12)\end{array}$ & $\begin{array}{c}.20 \\
(.05, .36)\end{array}$ & $\begin{array}{c}.09 \\
(.06, .23)\end{array}$ & $\begin{array}{c}.00 \\
(-.14, .14)\end{array}$ & $\begin{array}{c}.34 \\
(.18, .48)\end{array}$ \\
\hline SHS(1) & $\begin{array}{c}-.05-.10 \\
(-.15, .07)\end{array}$ & $\begin{array}{c}-.04 \\
(-.03, .06)\end{array}$ & $\begin{array}{c}.04 \\
(-.09, .18)\end{array}$ & $\begin{array}{c}-.09 \\
(-.21, .03)\end{array}$ & $\begin{array}{c}-.05 \\
(-.16, .08)\end{array}$ & $\begin{array}{c}-.05 \\
(-.17, .08)\end{array}$ \\
\hline SHS(2) & $\begin{array}{c}.03 \\
(-.05,-.11)\end{array}$ & $\begin{array}{c}-.12 \\
(-.25, .04)\end{array}$ & $\begin{array}{c}.02 \\
(-.12, .07)\end{array}$ & $\begin{array}{c}.00 \\
(-.09, .09)\end{array}$ & $\begin{array}{c}-.03 \\
(-.12, .07)\end{array}$ & $\begin{array}{c}-.01 \\
(-.11, .09)\end{array}$ \\
\hline SHS(3) & $\begin{array}{c}-.03 \\
(-.05,-.11)\end{array}$ & $\begin{array}{c}.07 \\
(-.08, .22)\end{array}$ & $\begin{array}{c}-.03 \\
(-.13, .07)\end{array}$ & $\begin{array}{c}-.04 \\
(-.12, .05)\end{array}$ & $\begin{array}{c}-.02 \\
(-.11, .07)\end{array}$ & $\begin{array}{c}-.06 \\
(.16, .04)\end{array}$ \\
\hline SHS(4) & $\begin{array}{c}.13 \\
(.01, .24)\end{array}$ & $\begin{array}{c}.16 \\
(-.03, .32)\end{array}$ & $\begin{array}{c}.03 \\
(-.10, .16)\end{array}$ & $\begin{array}{c}.04 \\
(-.07, .16)\end{array}$ & $\begin{array}{c}.12 \\
(-.07, .16)\end{array}$ & $\begin{array}{c}.10 \\
(-.04, .23)\end{array}$ \\
\hline RAS & $\begin{array}{c}-.29 \\
(-.42,-.15)\end{array}$ & $\begin{array}{c}-.14 \\
(-.35, .06)\end{array}$ & $\begin{array}{c}.70 \\
(.53, .86)\end{array}$ & $\begin{array}{c}.06 \\
(-.08, .20)\end{array}$ & $\begin{array}{c}.07 \\
(-.07, .21)\end{array}$ & $\begin{array}{c}.13 \\
(.02, .48)\end{array}$ \\
\hline RAS(1) & $\begin{array}{c}.03 \\
(-.05, .12)\end{array}$ & $\begin{array}{c}-.14 \\
(-.08, .00)\end{array}$ & $\begin{array}{c}-.03 \\
(-.12, .08)\end{array}$ & $\begin{array}{c}.04 \\
(-.05, .12)\end{array}$ & $\begin{array}{c}-.10(.02 \\
(-.19,-.02)\end{array}$ & $\begin{array}{c}.17 \\
(.09, .26)\end{array}$ \\
\hline RAS(2) & $\begin{array}{c}.02 \\
(-.05, .09)\end{array}$ & $\begin{array}{c}.02 \\
(-.10, .13)\end{array}$ & $\begin{array}{c}-.06 \\
(-.14, .03)\end{array}$ & $\begin{array}{c}-.04 \\
(-.11, .03)\end{array}$ & $\begin{array}{c}-.01 \\
(-.09, .07)\end{array}$ & $\begin{array}{c}.03 \\
(-.05, .11)\end{array}$ \\
\hline $\operatorname{RAS}(3)$ & $\begin{array}{c}-.00 \\
(-.08, .08)\end{array}$ & $\begin{array}{c}.04 \\
(-.08, .17)\end{array}$ & $\begin{array}{c}.01 \\
(-.08, .10)\end{array}$ & $\begin{array}{c}.02 \\
(-.07, .11)\end{array}$ & $\begin{array}{c}.03 \\
(-.07, .11)\end{array}$ & $\begin{array}{c}.11 \\
(.01, .20)\end{array}$ \\
\hline
\end{tabular}




\begin{tabular}{|l|c|c|c|c|c|c|}
\hline RAS(4) & .06 & .19 & .10 & .03 & .12 & -.26 \\
& $(-.07, .19)$ & $(-.03, .39)$ & $(-.05, .25)$ & $(-.11, .16)$ & $(-.02, .26)$ & $(-.39,-.13)$ \\
\hline RAS(5) & .02 & -.33 & .14 & .08 & -.14 & 0.25 \\
& $(-.06, .11)$ & $(-.23, .05)$ & $(-.17, .02)$ & $(-.09, .08)$ & $(-.10, .09)$ & $(-.13, .06)$ \\
\hline RAS(6) & -.29 & .16 & .37 & -.00 & -.02 & -.07 \\
& $(-.42,-.17)$ & $(-.04, .33)$ & $(.23, .51)$ & $(-.13, .13)$ & $(-.15, .12)$ & $(-.21, .07)$ \\
\hline RAS(7) & .14 & -.14 & -.27 & -.04 & .04 & -.06 \\
& $(-.00, .27)$ & $(-.35, .05)$ & $(-.44,-.12)$ & $(-.18, .09)$ & $(-.10, .18)$ & $(-.20, .08)$ \\
\hline BRS & .12 & -.33 & .14 & .08 & -.14 & .25 \\
& $(.01, .24)$ & $(-.51, .15)$ & $(-.01, .28)$ & $(-.05, .19)$ & $(-.27,-.03)$ & $(-.12, .38)$ \\
\hline BRS(1) & -.03 & .09 & -.03 & .14 & -.01 & .04 \\
& $(-.13, .08)$ & $(-.09, .24)$ & $(-.14, .07)$ & $(-.00, .27)$ & $(-.12, .10)$ & $(-.08, .17)$ \\
\hline BRS(2) & .00 & -.01 & -.00 & .19 & .03 & -.00 \\
& $(-.14, .11)$ & $(-.19, .18)$ & $(-.13, .13)$ & $(-.09, .31)$ & $(-.09, .15)$ & $(-.14, .12)$ \\
\hline BRS(3) & .01 & -.03 & -.04 & -.01 & -.06 & -.12 \\
& $(-.09, .12)$ & $(-.21, .16)$ & $(-.07, .04)$ & $(-.15, .08)$ & $(-.18, .06)$ & $(-.25, .00)$ \\
\hline BRS(4) & -.02 & .05 & -.00 & -.00 & -.05 & -.09 \\
& $(0.12, .07)$ & $(-.13, .22)$ & $(-.12, .11)$ & $(-.11, .11)$ & $(-.16, .04)$ & $(-.20, .02)$ \\
\hline BRS(5) & .02 & -.12 & -.06 & -.00 & .00 & .17 \\
& $(-.10, .13)$ & $(-.33, .01)$ & $(-.20, .07)$ & $(-.13, .12)$ & $(-.12, .12)$ & $(-.03, .30)$ \\
\hline BRS(6) & .17 & .02 & .01 & .12 & .08 & .03 \\
& $(-.03, .30)$ & $(-.08, .12)$ & $(-.16, .18)$ & $(.01, .23)$ & $(-.00, .09)$ & $(-.08, .14)$ \\
\hline
\end{tabular}

Based on H. Christensen, A.F. Jorm, A.J. Mackinnon, A.E. Korten, P.A. Jacomb, A.S. Henderson and B. Rodgers "Age Differences in depression and anxiety symptoms: a structural equation modelling analysis of data from a general population sample,' Psychological Medicine 1999, 99, 235-339.

As indicated in Table 2 significant effects are bold numbers. Rather than discussing the results by individual constructs, a covariate-approach by focusing on individual independent direct variable effects (Christensen et al., 1999) is presented. Specifically, the covariates are presented in the order of their prevalence as significant direct predictors of any of the seven models:

i. Socio-economic status had a significant positive direct effect on six of the models: SWL, SHS, BRS and the three augmented constructs: SWB (SWL, SHS), IES (RAS, BRS) and the third-order construct. Comparatively, the strongest effects are on SWL and SHS;

ii. The unstandardized direct effects of marital status are significantly associated with the four original constructs (SWL, SHS, RAS, BRS) and the two-second order constructs, SWB and IES. The largest direct effect of.70 for RAS is associated with the difference between married and others;

iii. To assess the differences in the direct effect of gender factor scores for each of the scores were computed. The results show that for RAS and two higher scores 
(IES and the Super Composite Construct), the average scores of female respondents are higher than those for males;

iv. The average construct scores were higher for younger respondents (aged between 18 and 39 years) for SWL and RAS;

v. Differences in scores by education is significant only for the SWL construct; average scores were higher for graduates than for non-graduates;

vi. Employment status is homogeneous for all the seven latent constructs. The second most homogeneous covariates are educational status and gender (about $90 \%$ are females).

\subsection{Differential Item Functioning (Direct Effects of Covariates on Individual Items)}

Table 2 provides the direct effects of individual covariates on individual items after controlling for the effects of the covariates on the construct. The labels are not bold, and the associated values are reported along with the $95 \%$ bootstrap confidence interval. The following section present the results for the three consistently significant covariates: age, marital status, and SES.

\section{Direct effects of AGE on individual items of the Constructs}

The zero/one coding converted respondents 18 to 39 years to 0 and over 49 years were coded a 1 . For construct SWL, two categories had significant differences at a p-value of.01: SWL(1) 'In most ways, my life is close to my ideal' and SWL(2) 'The conditions of my life are excellent.' For the former, after controlling for the effect of the set of six covariates on the satisfaction of life scale (SWL), the coefficient for older respondents was on the average about $14 \%$ higher than those for the young. The difference was far higher for respondents who believe their conditions were excellent; it was about $76 \%$ better than for the rest population. The third significant difference between young respondents and older respondents, holding constant the effects of the covariates on the construct, is the sixth item in the RAS construct - RAS(6) 'How much do you love your partner?'. The effect is about $29 \%$ stronger for younger than older participants in the survey. The second dependent variable with some significant effects on some items of the construct is the marital status of the respondent: SWL(4) 'So far, I have gotten all the important things in life' and RAS(6) 'How much do you love your partner?' In both cases, the effects are more substantial for married than unmarried respondents'; $21.6 \%$ and $37.4 \%$, respectively. The third covariate is SES with significant differences between low- and high-status respondents. In response to the questions RAS(1) 'How well does your partner meet your needs?' and RAS(5) 'To what extent has your relationship met your original expectations?'. The percentages are 17.2 and 24.8, respectively. However, for RAS(4) 'How often do you wish you had not gotten into this relationship?' the effect was higher for low-status respondents, by $25.7 \%$. 


\section{Discussion \& Conclusion}

The current investigation conceptualizes Subjective well-being (SWB) as a tripartite model consisting of overall life satisfaction (LS), positive affect (PA), and the relative absence of negative affect (NA). Scholars reviewed these components extensively. Recently, Moore and Diener (2019) identified a limitation with the tripartite model and indicated that an issue "...emerges in that most studies do not examine all three aspects at once." (p.1). Moore and Diener suggested that a study about relationship satisfaction might examine this about life satisfaction and negative affect, but do not include any aspects of positive affect. They suggest that "a more thorough understanding of how all three aspects of SWB relate to various relationship outcomes fills a need within the literature" (p.2). The components of SWB have been demonstrated as independent, and as such, can relate differently to outcomes associated with relationship, personal setbacks, across the different phases of life.

The focus on life satisfaction (LS) as measured by satisfaction with life scale (SWLS) and subjective happiness scale (SHS). The current investigation expands on Larwin et al. (2020) by demonstrating the linkages to other potential aspects of the characteristics of happy people; success in sexual and social relationships and exhibit the proclivity to rebound successfully from disappointing encounters. These more "global" aspects of well-being and life-satisfaction, as suggested by Diener (2002) and later demonstrated by Galinha and Pais-Ribeiro (2008) are measured via the relationship assessment scale (RAS) and the latter by the brief resilience scale (BRS). These two personal experience scales are used to create an Augmented Satisfaction with Life Scale (ASWLS) as presented in Larwin et al.

For both the covariance-based and the MIMIC models with six covariates, three sets of models were tested: four single factor structural equations models for each of the constructs, pairs of two second-order factor models; SWL with SHS; and BRS with RAS. Finally, an alternate hierarchical model was tested using structural equations. For both sets of models, the models fitted the data with varying degrees of fit. The hierarchical models (covariance and MIMIC) all fitted the data, and for both cases, the second-order correlated models exhibited the best fit. The third-order model (Figure 3) included the explained variances of the second-order models that generate the third. The figures for the hierarchical models display the loadings for the constructs and the significance of the hypothesized effects. The hierarchical modeling provided alternate models for assessing nested processes under different scenarios. The single factor model used is one of the simpler MIMIC models.

An additional issue that was addressed are the implications of applying factor analytic approaches, that assume homogeneity of the input to heterogeneous survey data. As discussed earlier, a MIMIC Model for each of the constructs decomposed into three effects: the factor loadings, the direct effects of a covariate on a latent variable, the indirect effect of the covariate on item (manifest variable) after controlling for the effects of the covariates on the latent variable. The latter two were evaluated using DIF (differential item functioning) which is a measure of 
how an item might be measured differently for subgroups. Average item scores for subgroups having the same overall score on the test must have the same score. However, where this is not the case then there is DIF; the item is not measuring the same way for all subgroups; effects of each covariate on the latent factor (DIF), and the indirect effects, which is the significant effect of a covariate on a manifest variable after controlling for the influence for the covariates on the construct (MIMIC DIF). The presence of any of these DIF-effects indicate heterogeneity and "as heterogeneity increases in a population, invariance of a particular measure becomes more difficult to achieve. Also, heterogeneity will increase the probability that items will function differently across groups within that population." (Mast \& Lichtenberg, 2000, p. 50).

At the scale level, Satisfaction with Life Scale (SWL) exhibited the most MIMIC DIF effects with four of the six covariates: age, marital status (not married or married), education level, and socioeconomic status. For the last three of these variables, the average differences in satisfaction with life (SWL) scores were largest between married and non-married respondents and between low and high economic status individuals. Regarding age, the heterogeneity reflects the fact that the average SWL scores for younger respondents were higher than for older respondents. For all four scales, the average effect of marital status on responses was significantly higher for married respondents than of those in any other partner relationships. The most substantial discrepancies were in the average direct SWL scores between nonmarried and married respondents. Significant effects indicate, according to Mast and Lichtenberg (2000), that one or more items within each factor or construct may be functioning in a systematically different manner than the rest of the items in that construct for a subgroup of the population. These different parameter values can result in non-invariance of factor structures at the level of factor loadings or measurement intercepts, which demonstrates that factors that are assumed to be similar across groups within a population are instead constructed somewhat differently. In other words, some items are more important for one group in defining a factor than they are for another group (pp. 50-51).

After controlling for the effects of the covariates on each of the four constructs, only two items are significant: "SWL(1) In most ways, my life is close to my ideal" (higher for the older respondents) and "RAS(6) How much do you love your partner?" (higher for the younger than for older respondents). For the gender independent variable, only one effect is significant: "RAS(5) To what extent has your relationship met your original expectations?" (significantly higher for males than females). The results for marital status, indicate that significant DIF occurs on "SWL(4) So far, I have gotten all the important things in life" (far higher for married respondents than those in other kinds of intimate relationships). Similar DIF is significant for "RAS(6) How much do you love your partner?". For the education variable, DIF is significant for only one item "BRS(2) I have a hard time making it through stressful events" (higher for the less educated). Finally, for the SES covariate, DIF effect is significant for three items: "RAS(1) How well does your partner meet your needs?" (higher for higher status respondents), "RAS(4) How 
often do you wish you had not gotten into this relationship?" (higher for lower status), and "RAS(5) To what extent has your relationship met your original expectations?" (significantly higher for high-status respondents).

Many other studies used the four scales employed in this paper, and their psychometric attributes have been tested and documented. The scarcity of DIF reflects the influence of such prior studies of these scales. The addition of DIF in the current investigation provides an important contribution to the SWB research. Future research using these four scale inventories should consider systematic item reduction. While these scales demonstrate good convergent and discriminant validity individuality (e.g., Busing \& West, 2016; Diener et al., 1985; Diener, Inglehart \& Tay, 2013; Dinkel \& Balck, 2005; Tay, Ng, Kuykendall, \& Diener, 2014; Vela, Lerma, \& Ikonomopoulos, 2017), used in conjunction with the other scales provides opportunities for reducing the overall number of items across the four scales (Larwin \& Harvey, 2012).

\section{References}

[1] Achour, M., and Nor, M. R. M. (2014). The effects of social and resilience on life satisfaction of secondary school students. Journal of Academic and Applied Studies, 4, 12-20.

[2] Andrews, F. M., and Withey, S. B. (1976). Social Indicators of Well-being: Americans' Perceptions of Life Quality. New York: Plenum Press.

[3] Badran, M. A., and Youssef-Morgan, C. M. (2015). Psychological capital and job satisfaction in Egypt. Journal of Managerial Psychology, 30, 354-370. doi:doi:10.1108/JMP-06-2013-0176.

[4] Brown, T. A. (2006). Confirmatory Factor Analysis for Applied Research. New York: Guilford Press.

[5] Busing, K., and West, C. (2016). Determining the relationship between physical fitness, gender, and life satisfaction. SAGE Open, 6. doi: $10.1177 / 2158244016669974$.

[6] Busseri, M. A., and Sadava, S. W. (2011). A review of the tripartite structure of subjective well-being: Implications for conceptualization, operationalization, analysis, and synthesis. Personality and Social Psychology Review, 15, 290-314. doi:10.1177/1088868310391271.

[7] Chaudhuri, K., Kumbhakar, S. C., and Sundaram, L. (2016). Estimation of firm performance from a mimic model. European Journal of Operational Research, 255, 298-307. doi:10.1016/J.EJOR.2016.05.005.

[8] Christensen, H., Jorm, A. F., Mackinnon, A. J., Korten, A. E., Jacomb, P. A., Henderson, A. S., and Rodgers, B. (1999). Age differences in depression and anxiety symptoms: A structural equation modelling analysis of data from a general population sample. Psychological Medicine, 29, 325-339.

[9] Diener, E. (1984). Subjective well-being. Psychological Bulletin, 95, 542-575. doi:10.1037/0033-2909.95.3.542.

[10] Diener, E. (2000). Subjective well-being. American Psychologist, 55, 34-43. 
[11] Diener, E. (2019). Happiness: The science of subjective well-being. Retrieved from https://nobaproject.com/modules/happiness-the-science-of-subjectivewell-being

[12] Diener, E., and Biswas-Diener, R. (2008). Happiness: Unlocking the Mysteries of Psychological Wealth. Malden, MA; Oxford: Blackwell Publishing.

[13] Diener, E., Emmons, R. A., Larsen, R. J., and Griffin, S. (1985).

The satisfaction with life scale. Journal of Personality Assessment, 49, 71-75.

[14] Diener, E., Inglehart, R., and Tay, L. (2013). Theory and validity of life satisfaction scales. Social Indicators Research, 112, 497-527. doi:10.1007/S11205-012-0076-Y.

[15] Dinkel, A., and Balck, F. (2005). An evaluation of the German relationship assessment scale. Swiss Journal of Psychology, 64, 259-263. doi:10.1024/1421-0185.64.4.259.

[16] Dutta, A., and Blangayil, F. (2016). A study exploring the relationship between subjective happiness \& life satisfaction. International Journal of Indian Psychology, 4, 207-222. doi:10.25215/0476.016.

[17] Eid, M., and Diener, E. (2006). Handbook of Multimethod Measurement in Psychology. Washington, DC: American Psychological Association.

[18] Galinha, I. C. C., and Pais-Ribeiro, J. L. (2008). The structure and stability of subjective well-being: A structure equation modelling analysis. Applied Research in Quality of Life, 3, 293-314. doi:10.1007/s11482-009-9063-0.

[19] Gallo, J. J., Rabins, P. V., and Anthony, J. C. (1999). Sadness in older persons: 13-year follow-up of a community sample in Baltimore, Maryland. Psychological Medicine, 29, 341-350.

[20] Guan, M. (2017). Measuring the effects of socioeconomic factors on mental health among migrants in urban China: A multiple indicators multiple. International Journal of Mental Health Systems, 11, 1-11. doi:10.1186/S13033-016-0118-Y.

[21] Hendrick, S. S. (1988). A generic measure of relationship satisfaction. Journal of Marriage \& Family, 50, 93-98.

[22] Hendrick, S. S., Dicke, A., and Hendrick, C. (1998). The relationship assessment scale. Journal of Social and Personal Relationships, 15, 137-142. doi:10.1177/0265407598151009.

[23] Jöreskog, K. G., and Goldberger, A. S. (1975). Estimation of a model with multiple indicators and multiple causes of a single latent variable. Journal of the American Statistical Association, 70, 631-639. doi:10.1080/01621459.1975.10482485.

[24] Krueger, A. B., and Schkade, D. A. (2008). The reliability of subjective wellbeing measures. Journal of Public Economics, 92, 1833-1845. doi:10.1016/J.JPUBECO.2007.12.015.

[25] Larwin, K., and Harvey, M. E. (2012). A demonstration of a systematic itemreduction approach using structural equation modeling. Practical Assessment, Research \& Evaluation, 17, 1-19. 
[26] Larwin, K.H., Harvey, M. E., and Constantinou, S. (2020). An Expanded Life Satisfaction Model: A component of Subjective Well-Being. The Journal of Methods and Measurement in the Social Sciences. 11(1), 25-44.

[27] López-Ortega, M., Torres-Castro, S., and Rosas-Carrasco, O. (2016). Psychometric properties of the satisfaction with life scale (SWLSWL): Secondary analysis of the Mexican health and aging study. Health and Quality of Life Outcomes, 14, 1-7. doi:10.1186/S12955-016-0573-9.

[28] Lucas-Carrasco,R., Den Oudsten, B. L., Eser, E., and Power, M. J. (2014). Using the satisfaction with life scale in people with Parkinson's disease: A validation study in different European countries. The Scientific World Journal, 7. doi:10.1155/2014/680659.

[29] Lyubomirsky, S. (2008). The How of Happiness : A New Approach to Getting the Life You Want. New York, N.Y.: Penguin Books.

[30] Lyubomirsky, S., and Lepper, H. S. (1999). A measure of subjective happiness: Preliminary reliability and construct validation. Social Indicators Research, 46, 137-155.

[31] Mahmood, K., and Ghaffar, A. (2014). The relationship between resilience, psychological distress and subjective well-being among dengue fever survivors. Global Journal of Human Social Science, 14, 13-20.

[32] Mast, B. T., and Lichtenberg, P. A. (2000). Assessment of functional abilities among geriatric patients. Rehabilitation Psychology, 45, 49-64. doi:10.1037//0090-5550.45.1.49.

[33] Moore, S., and Diener, E. (2019). Types of subjective well-being and their associations with relationship outcomes. Journal of Positive Psychology and Wellbeing, 1-12.

[34] Patil, A. P., and Adsul, R. K. (2017). A correlational study on resilience and well-being among college adolescents in Kolhapur city. Indian Journal of Positive Psychology, 8, 83-86.

[35] Pavot, W., and Diener, E. (1993). Review of the satisfaction with life scale. Psychological Assessment, 5, 164-172. doi:10.1037//1040-3590.5.2.164.

[36] Post, M. W., van Leeuwen, C. M., van Koppenhagen, C. F., and de Groot, S. (2012). Validity of the life satisfaction questions, the life satisfaction questionnaire, and the satisfaction with life scale in persons with spinal cord injury. Archives of Physical Medicine and Rehabilitation, 93, 1832-1837. doi:10.1016/J.APMR.2012.03.025.

[37] Proitsi, P., Hamilton, G., Tsolaki, M., Lupton, M., Daniilidou, M., Hollingworth, P., . . Powell, J. F. (2011). A multiple indicators multiple causes (mimic) model of behavioural and psychological symptoms in dementia (bpsd. Neurobiology of Aging, 32, 434-442. doi:10.1016/J.NEUROBIOLAGING.2009.03.005.

[38] Renshaw, K. D., McKnight, P., Caska, C. M., and Blais, R. K. (2011). The utility of the relationship assessment scale in multiple types of relationship. Journal of Social and Personal Relationships, 28, 435-447. doi:10.1177/0265407510377850. 
[39] Ríos-Bedoya , C. F., Pomerleau, C. S., Neuman, R. J., and Pomerleau, O. F. (2009). Using mimic models to examine the relationship between current smoking and early smoking experiences. Nicotine \& Tobacco Research, 11, 1035-1041. doi:10.1093/ntr/ntp093.

[40] Robbins, J. M., Ford, M. T., and Tetrick, L. E. (2011). Perceived unfairness and employee health. Journal of Applied Psychology, 97, 235-272. doi:10.1037/A0025408.

[41] Sagone, E., and Caroli, M. E. D. (2014). Relationships between psychological well-being and resilience in middle and late adolescent. Procedia - Social and Behavioral Sciences, 141, 881-887. doi:10.1016/J.SBSPRO.2014.05.154.

[42] Slocum-Gori, S. L., Zumbo, B. D., Michalos, A. C., and Diener, E. (2009). A note on the dimensionality of quality of life scales: An illustration with the satisfaction with life scale (SWLSWL). Social Indicators Research, 92, 489496. doi:10.1007/S11205-008-9303-Y.

[43] Souri, H., and Hasanirad, T. (2011). Relationship between resilience, optimism and psychological well-being in students of medicine. Procedia - Social and Behavioral Sciences, 30, 1541-1544. doi:10.1016/J.SBSPRO.2011.10.299.

[44] Tansey, T. N., Kaya, C., Moser, E., Eagle, D., Dutta, A., and Chan, F. (2016). Psychometric validation of the brief resilience scale in a sample of vocational rehabilitation consumers. Rehabilitation Counseling Bulletin, 59, 108-111. doi:10.1177/0034355215573539.

[45] Tay, L., Ng, V., Kuykendall, L., and Diener, E. (2014). Demographic factors and worker well-being: An empirical review using representative data from the United States and across the world. In P. L. Perrewé, C. C. Rosen, J. R. B. Halbesleben (Eds.), The Role of Demographics in Occupational Stress and Well Being (pp. 235-283). Bingley, UK: Emerald Group Publishing Limited.

[46] Vela, J. C., Lerma, E., and Ikonomopoulos, J. (2017). Evaluation of the life satisfaction and subjective happiness scales with Mexican American high school and college students. Hispanic Journal of Behavioral Sciences, 39, 3445. doi:10.1177/0739986316681298.

[47] Wang, J., and Wang, X. (2012). Structural Equation Modeling : Applications Using Mplus. Chichester, West Sussex [England]; Hoboken, N.J.: John Wiley/Higher Education Press. 